\title{
Análise comparativa de redes interfirmas de instituições de ensino superior
}

Gislaine Barbosa Zaneti

gis_zaneti@ig.com.br

José Paulo Alves Fusco

jpafusco@uol.com.br

Regina Ferreira da Rocha

regina.rfr@bol.com.br

\section{RESUMO}

As organizações enfrentam diversos desafios para sobreviver em um mundo em constante transformação. Nesse sentido, novos modelos de gestão precisam ser incorporados à dinâmica organizacional, visando à obtenção de vantagens competitivas. As redes de empresas estabelecem uma forma particular de cooperação como elemento primordial, podendo existir vínculos de diversas naturezas a justificar os relacionamentos. Trata-se de arranjos interorganizacionais ou interfirmas, formados por atores que mantêm relacionamentos com o intuito de melhorar o desempenho final da rede e dos envolvidos. Assim, as Instituições de Ensino consideradas organizações que têm por finalidade disseminar conhecimento e formar profissionais que contribuam para o crescimento de uma nação também fazem uso desse tipo de arranjo. Em face das questões levantadas, este artigo tem por objetivo demonstrar a aplicabilidade de uma técnica de mapeamento de redes de empresas em Instituições de Ensino Superior. Como resultado, demonstrar a possibilidade de se proceder a análises comparativas entre a intensidade dos relacionamentos observados em duas instituições pesquisadas, uma privada e outra pública, localizadas no Estado de São Paulo. Mediante o uso da análise comparativa, o artigo apresenta também uma análise do relacionamento entre os atores de níveis estratégico e tático de cada instituição, considerando-se as especificidades de cada uma.

Palavras-chave: Redes; Redes interfirmas; Instituição de Ensino Superior; Intensidade de relacionamentos.

\section{Comparative analysis of inter-firm networks in higher education institutions}

\begin{abstract}
Organizations have been facing several challenges to survive in a world in constant transformation. In light of that, new management models need to be incorporated to the organizational dynamics in order to achieve competitive advantages. The inter-firm networks establish a particular form means of cooperation as a fundamental element, as there can be ties of diverse nature to justify the relationships. These are interorganizations or inter-firms, formed by people who maintain the relationships to improve the overall performance of the network and of the participants. Thus, the Education Institutions, considered as organizations, which have the objective to disseminate knowledge and form professionals who contribute to the growth of a nation, also make use of this type of arrangement. Considering the raised questions, this article aims to demonstrate the applicability of a business network mapping technique at Higher Education Institutions. It also presents the possibility to perform the comparative analysis of the intensity of the relationship observed in a private and in a public institution, in the State of São Paulo. By applying the comparative analysis, this study also presents the relationship among the people involved at strategic and tactical levels of each institution, taking into account each one's peculiarities.
\end{abstract}

Key words: Networks; Inter-firm networks; Higher Education Institutions; Relationship Intensity. 


\section{Introdução}

A educação representa fator preponderante para uma nação democrática, autônoma e soberana, por promover igualdade nas oportunidades sociais e produzir capital intelectual tão importante num cenário globalizado e altamente competitivo. Dessa forma, a educação superior tem papel essencial para a formação de profissionais qualificados, além de contribuir com pesquisas inovadoras que favoreçam ao desenvolvimento tecnológico.

Segundo o Censo da Educação Superior de 2009, divulgado pelo Instituto de Estudos e Pesquisas Educacionais Anísio Teixeira (INEP), há 2.314 instituições de educação superior, dessas 245 públicas e 2.069 particulares, sendo 186 universidades, 127 centros universitários, 35 institutos e 1.966 faculdades. Crescimento de 3,8\% no número de instituições públicas e $2,6 \%$ no de particulares, em um ano.

Diante do crescimento do segmento de Instituições de Ensino Superior (IES), novos modelos de gestão podem ser adotados com o intuito de otimizar seus processos e auxiliar na obtenção de vantagens competitivas.

No cenário apresentado, a aplicação do conceito de redes de empresas favorece cada organização ou ator, pertencente à rede, de modo a focalizar e direcionar seus esforços para a sua atividade principal, enquanto as organizações parceiras estão comprometidas com o desenvolvimento das atividades secundárias ou não prioritárias. Nesse sentido, é necessário conhecer os atores que podem contribuir para os resultados da rede, possibilitando seu mapeamento.

Desse modo, o objetivo deste artigo foi demonstrar a aplicabilidade da técnica de mapeamento de redes de empresas em Instituições de Ensino Superior, visando obter elementos que permitam a análise comparativa entre as intensidades dos relacionamentos nos recortes das redes das instituições pesquisadas.

\section{Método de pesquisa}

Os procedimentos adotados como método de pesquisa são a pesquisa referencial e o estudo de caso. A pesquisa referencial ocorreu a partir de pesquisas em livros e artigos de periódicos, com o intuito de coletar informações e conhecimentos prévios sobre o assunto abordado e de fundamentar os principais conceitos.
Com relação ao estudo de caso, Miguel (2010) comentou que esse estudo investiga dado fenômeno dentro de um contexto real, por meio de uma análise profunda, possibilitando amplo e detalhado conhecimento sobre o fenômeno. Neste artigo, procurou-se apresentar uma síntese da análise da aplicabilidade do mapeamento de redes de empresas, fazendo descrição dessa aplicação num contexto real (instituições de ensino superior), permitindo apresentar análises das características dos processos organizacionais dessas instituições.

Uma das Instituições de Ensino Superior estudadas é a Faculdade de Agudos (FAAG). Essa instituição iniciou suas atividades em 2002 e, atualmente, conta com quatro cursos de graduação e cursos de pós-graduação lato sensu, atendendo 423 alunos de graduação e 296 de pós-graduação.

A outra Instituição de Ensino Superior é a Faculdade de Tecnologia de Garça (Fatec), em atividade desde 2004. Essa instituição oferece cinco cursos de graduação, atendendo 1.019 alunos. A Fatec Garça é uma das unidades de ensino do Centro Estadual de Educação Tecnológica Paula Souza (CEETEPS), entidade autárquica presente em 157 municípios do Estado de São Paulo, com 52 Fatec's e 203 Escolas Técnicas Estaduais (ETECs), totalizando 271.000 alunos.

Para a FAAG, estabeleceu-se como limite para a pesquisa um recorte de 10 atores, sendo nove de nível estratégico e um ator de nível operacional: Mantenedora, Diretoria Acadêmica, Diretoria Administrativa, Coordenação de Pesquisa e Extensão, três Coordenadores de Cursos de Graduação, dois Coordenadores de Cursos de PósGraduação e Secretaria Acadêmica.

Para a Fatec Garça, estabeleceu-se o recorte de nove atores, dos quais três compõem o nível estratégico, três o nível tático e três o nível operacional, assim denominados: Diretoria Geral, Diretoria Acadêmica, Diretoria de Serviços Administrativos, três Coordenadores de Cursos de Graduação e três Coordenadores de Estágio.

Os dados e informações para análise do recorte avaliado das redes e dos relacionamentos entre os atores das instituições foram obtidos mediante entrevistas semiestruturadas.

\section{Redes de empresas}

Um novo paradigma conhecido por rede de empresas diz respeito a um modo de agrupamento de empresas destinado a fortalecer cada participante da rede, sem que haja a necessidade de estabelecer 
laços financeiros entre si. Dessa forma, as empresas em rede complementam-se umas às outras nos aspectos técnicos e mercadológicos e decidem apoiar-se mutuamente em prioridade.

Ao abordar a definição de rede, Fusco et al. (2005) comentaram que uma rede de negócios é um grupo de negócios que coopera e colabora na procura de novas oportunidades de negócios e envolve a cooperação entre as empresas, para empreender projetos e colaborar para o alcance dos objetivos que cada uma das empresas não pode conseguir, independentemente.

Segundo Britto (2002, p. 351), os elementos morfológicos presentes na estrutura de uma rede são: os nós, as ligações, as posições e os fluxos.

Os nós podem ser descritos como empresas ou atividades entre empresas, demonstrados pelos pontos circulares na Figura 1. As posições definem as localizações das empresas ou atividades na estrutura da divisão de trabalho dos diferentes agentes, necessárias à produção de bens envolvendo a integração de capacidades operacionais, competências e tecnologias, como demonstrado na Figura 1 pelas diferenças entre os pontos circulares. As ligações, conexões ou linkages determinam o relacionamento entre empresas em aspectos qualitativos, o grau de densidade ou a qualidade do relacionamento dos agentes de uma rede, demonstrados pela espessura das ligações entre os atores (Figura 1). Os fluxos tangíveis ou de bens (insumos e produtos) e intangíveis ou de informações fluem através das ligações (BRITTO, 2002, p. 352; SACOMANO NETO, 2004).

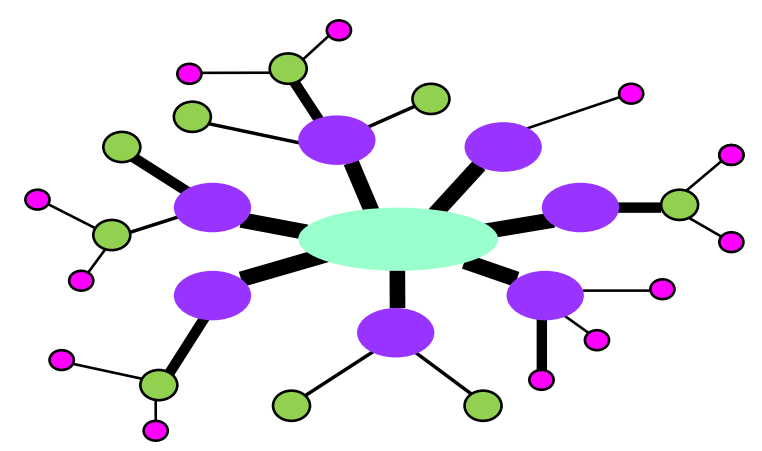

Figura 1 - Elementos presentes na estrutura de uma rede

Fonte: Adaptado de SACOMANO NETO, 2004.

Ao observar as ligações entre os nós, é possível caracterizar a densidade e centralização da rede, medidas que indicam em que forma a rede está estruturada.

Para Britto (2002, p. 354), a densidade pode estar associada à relação entre o número de ligações observadas e o número máximo de ligações que poderiam ocorrer. Já Lima (2009) destacou que o conceito de densidade é entendido através da intensidade da interconexão entre os atores da rede. Quanto maior a interconexão, maior a densidade.

Segundo Lazzarini (2008, p. 21), "a rede é densa quando vários atores estão conectados entre si”. As redes densas, em que o grau de interconexão é constante e forte entre os atores, facilitam o fluxo de informações e outros recursos, funcionando como sistemas fechados de confiança e facilitando a atribuição de sanções. As redes difusas originam-se quando o grau de interconexão é menor, inconstante e fraco entre os atores (LIMA, 2009). Os conceitos de rede densa e rede difusa são essenciais para o estudo das redes de fornecimento, pois permitem compreender qual posição é mais adequada ao contexto de uma organização (SACOMANO NETO, 2004).

\section{Relacionamentos}

Gattorna e Walters (1996) sugeriram uma tipologia para mapeamento e avaliação do nível dos relacionamentos entre os atores de uma rede. Conforme observado no Quadro 1, no modelo de mapeamento indicado por esses autores há quatro níveis principais, que classificam os relacionamentos nas redes por grau de importância das transações operacionais de quem presta o serviço e de quem o recebe. Para os referidos autores, os extremos de um relacionamento são definidos como "fornecedor" e "comprador" do que está sendo desenvolvido.

Quadro 1 - Mapeamento das relações de dependência

\begin{tabular}{|c|c|c|}
\hline Nível & Fornecedor & Comprador \\
\hline 1 & Alto & Alto \\
2 & Alto & Baixo \\
3 & Baixo & Alto \\
4 & Baixo & Baixo \\
\hline
\end{tabular}
Fonte: GATTORNA; WALTERS, 1996.

Segundo aqueles autores, nos níveis 1 e 4 não existe conflito ou abuso de poder, pois há equilíbrio de interesses entre os parceiros. Mas, nos níveis 2 e 3 , o potencial de conflito ou a possibilidade de abuso de poder por parte do ator mais forte do relacionamento é grande. Se os relacionamentos forem classificados nos níveis em que pode haver o desequilíbrio de interesses ou de poder, esses mesmos autores sugeriram que uma aliança deve ser tratada mais estrategicamente.

Matematicamente, uma rede é uma matriz onde cada célula indica como um ator que está em linha se relaciona com outro que está em coluna, 
sendo, desse modo, a relação codificada como existente ou não existente (LAZZARINI, 2008).

$\mathrm{Na}$ abordagem de rede social, apresentada na teoria de rede por Granovetter (1983, p. 201), os conhecidos são denominados laços fracos e os amigos, laços fortes. No relacionamento com conhecidos (laços fracos), a rede é de baixa densidade, ou seja, muitas das possíveis linhas relacionais estão ausentes, enquanto no relacionamento com amigos (laços fortes) a rede é densa, pois muitas das possíveis linhas relacionais estão presentes. Dessa forma, as pessoas com poucos laços fracos serão privadas de informações de partes distantes do seu sistema social, ficando confinada a notícias e pontos de vista de seus amigos (GRANOVETTER, 1983, p. 202). Trazendo essa abordagem para as organizações, a privação dessas informações poderá colocar a organização em posição de desvantagem no mercado, em que a eficácia em atingir determinados objetivos pode depender da rapidez e facilidade com que se obtém uma informação.

Em seus estudos, Granovetter (1973) relatou que é possível atribuir intensidade ou força aos relacionamentos. Lazzarini (2008, p. 18) citou como exemplo da atribuição dessa intensidade o número de vezes que duas pessoas se encontram por semana para trocar ideias, sendo quanto maior a frequência dos encontros, maior a intensidade dos relacionamentos.

\section{Mensuração da intensidade de relacionamentos}

Para realizar a análise comparativa da intensidade dos relacionamentos em duas instituições de ensino superior, foi necessário levantar as principais atividades desempenhadas pelos atores que contribuem para fortalecer as operações da rede intraorganizacional dessas instituições de ensino.

As principais atividades desempenhadas pelos atores que fazem parte do recorte avaliado da rede foram coletadas em entrevistas semiestruturadas e organizadas em quadros distintos de cada ator entrevistado, conforme modelo do Quadro 2. Além das principais atividades, esse quadro apresenta a qual ator cada atividade se destina ou qual ator depende da atividade, podendo ser a um ou mais atores. Cada atividade, relacionada pela ordem em que foi mencionada durante a entrevista, recebeu um número como identificação.
Quadro 2 - Modelo de organização das principais atividades desenvolvidas pelos atores entrevistados

\begin{tabular}{|c|l|l|}
\hline \multicolumn{3}{|l|}{ Ator entrevistado } \\
\hline $\mathbf{N}^{\mathbf{0}}$ & Principais atividades desenvolvidas & Destinatário \\
\hline 1 & Atividade 1 & Ator 1 \\
\hline$\vdots$ & Atividade ... & $\begin{array}{l}\text { Ator } 1 \\
\text { Ator } 2\end{array}$ \\
\hline 15 & Atividade 15 & $\begin{array}{l}\text { Ator } 4 \\
\text { Ator } 8\end{array}$ \\
\hline
\end{tabular}

Fonte: Elaborado pelos autores.

Tomando por base o conceito de intensidade dos relacionamentos de Granovetter (1983), a intensidade dos relacionamentos entre os atores do recorte avaliado da rede foi mensurada considerando a frequência com que um destinatário é mencionado na relação de principais atividades desenvolvidas por esse ator, demonstrando, assim, o grau de intensidade desse relacionamento, conforme demonstrado na Tabela 1. Assim, se o destinatário "Ator 2" for mencionado cinco vezes nas principais atividades desenvolvidas pelo "Ator 1" e o destinatário "Ator 3" for mencionado duas vezes, o destinatário "Ator 2", mais mencionado, será considerado mais importante do que o "Ator 3", menos mencionado, demonstrando que o grau de intensidade do relacionamento do destinatário "Ator 2" é maior que o "Ator 3".

Tabela 1 - Proposta para mensurar a intensidade dos relacionamentos

\begin{tabular}{|c|c|c|}
\hline Ator & Destinatários & Frequência \\
\hline \multirow{4}{*}{ Ator 1} & Ator 2 & 5 \\
& Ator 3 & 2 \\
& $\vdots$ & $\vdots$ \\
& Ator 20 & 2 \\
\hline$\vdots$ & $\vdots$ & $\vdots$ \\
& $\vdots$ & $\vdots$ \\
\hline \multirow{2}{*}{ Ator 10} & Ator 1 & 5 \\
& Ator 2 & 3 \\
\hline
\end{tabular}

Fonte: Elaborado pelos autores.

\section{Análise comparativa}

Com as informações das principais atividades desenvolvidas pelos atores entrevistados, foi possível mapear o recorte avaliado da rede das duas instituições e representar esse mapeamento graficamente. A representação gráfica foi realizada com o auxílio do software Ucinet ${ }^{\circledR} 6$ para Windows versão 6.320 específico para essa finalidade, que apresenta os relacionamentos entre os atores entrevistados e os demais atores internos e externos 
que compõem o recorte avaliado de cada rede, demonstrando a intensidade dos relacionamentos entre os atores, conforme observado na Figura 2 para a rede da FAAG e na Figura 3 para a rede da Fatec Garça.

Na Figura 2 e na Figura 3, os elementos morfológicos nós, ligações, posições e fluxos presentes na estrutura da rede podem ser visualizados (BRITTO, 2002; SACOMANO NETO, 2004). Os nós, que são os atores internos e externos da instituição, estão representados pelas figuras geométricas coloridas e identificados na legenda de cada figura. As posições, que definem as localizações dos atores na estrutura da rede, são observadas pela posição em que cada ator se encontra na respectiva figura. Os atores que mais se relacionam estão concentrados no centro das figuras, e os com menos relacionamentos se posicionam nas extremidades de cada figura. Os fluxos das atividades desenvolvidas pelos atores que fluem por meio das ligações são representados pelas setas que se encontram nas ligações.

A intensidade dos relacionamentos, identificada pela espessura e cores das linhas que conectam os atores relacionados na Figura 2 e na Figura 3, foi mensurada segundo a proposta da Tabela 1, onde se considerou a frequência com que um destinatário foi mencionado pelo ator entrevistado na coleta das principais atividades por ele desenvolvidas.
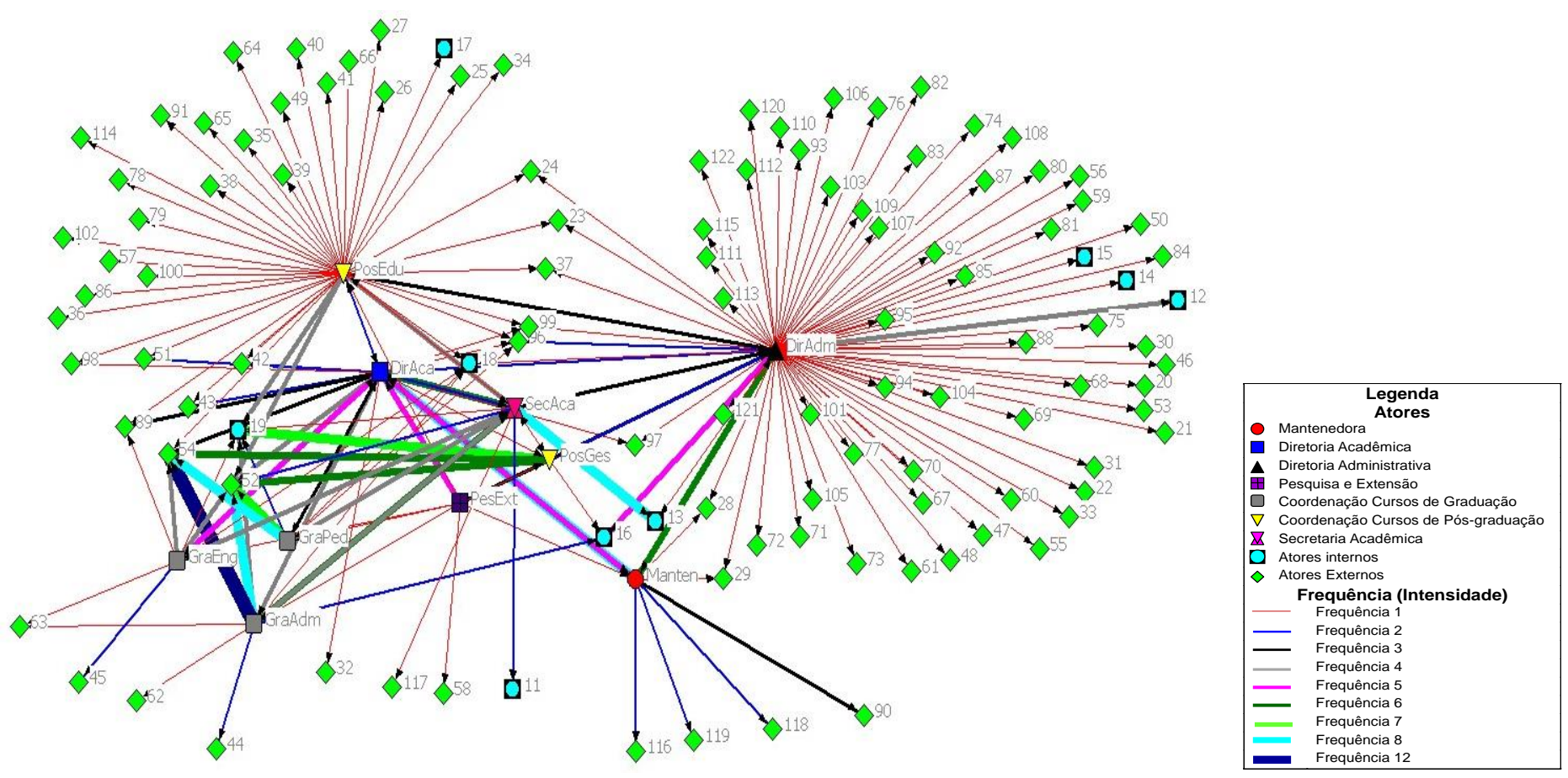

Figura 2 - Representação gráfica do recorte avaliado da rede da FAAG

Foram identificados 122 atores no recorte avaliado da rede da FAAG, sendo 10 internos entrevistados, nove internos não entrevistados e 103 externos mencionados durante as entrevistas. 


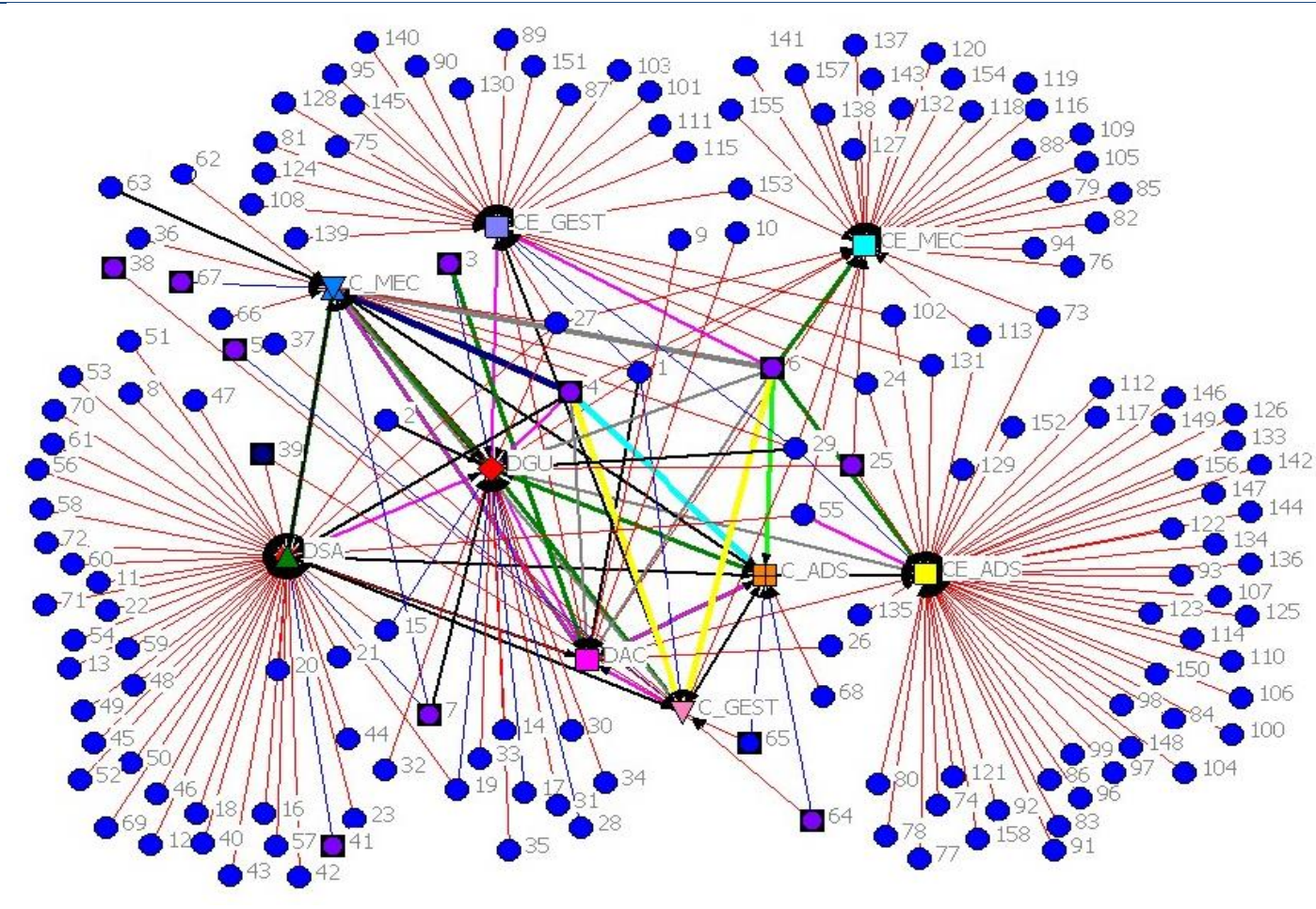

\begin{tabular}{|c|c|}
\hline & $\begin{array}{l}\text { Legenda } \\
\text { Atores }\end{array}$ \\
\hline & Diretoria Geral \\
\hline$\Delta$ & Diretoria de Serviços \\
\hline$\square$ & Diretoria Acadêmica \\
\hline 田 & Coordenação dos Cursos - ADS e TIGN \\
\hline & Coordenação do Curso de Gestão \\
\hline 善 & Coordenação dos Cursos de Mecatrônica e Produção \\
\hline 口 & $\begin{array}{l}\text { Coordenação Estágio ADS e TIGN } \\
\text { lats }\end{array}$ \\
\hline 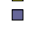 & Coordenação de Estágio Gestão \\
\hline$\square$ & Coordenação de Estágio Mecatrônica e Produção \\
\hline & Atores Internos \\
\hline$\bullet$ & Atores Externos \\
\hline & Frequência (intensidade) \\
\hline ـ & Frequência 1 \\
\hline & Frequência 2 \\
\hline & Frequência 3 \\
\hline- & Frequência 4 \\
\hline & Frequência 5 \\
\hline & Frequência 6 \\
\hline & Frequência 7 \\
\hline & Frequência 8 \\
\hline & Frequência 9 \\
\hline & Frequência 10 \\
\hline & Frequência 11 \\
\hline & Frequência 12 \\
\hline
\end{tabular}

Figura 3 - Representação gráfica do recorte avaliado da rede da Fatec Garça

Ao avaliar o recorte da rede da Fatec Garça, foram identificados 167 atores, sendo nove internos entrevistados, 10 internos não entrevistados e 148 externos mencionados nas entrevistas.

Os principais aspectos utilizados na análise comparativa são apresentados no Quadro 3, a partir do qual as considerações a seguir foram fundamentadas.

Quadro 3 - Síntese da análise comparativa

\begin{tabular}{|c|c|c|}
\hline Características & FAAG & Fatec garça \\
\hline Cursos graduação & 4 & 5 \\
\hline Cursos pós-graduação & 5 & 0 \\
\hline Alunos de graduação & 423 & 1019 \\
\hline $\begin{array}{l}\text { Alunos de pós- } \\
\text { graduação }\end{array}$ & 296 & 0 \\
\hline Recorte avaliado & 122 & 167 \\
\hline Atores entrevistados & 10 & 9 \\
\hline Atores internos & 9 & 10 \\
\hline Atores externos & 103 & 148 \\
\hline Ator central da rede & $\begin{array}{l}\text { Diretoria } \\
\text { Acadêmica }\end{array}$ & Diretoria Geral \\
\hline Grau de interconexão & $\begin{array}{l}\text { Denso no } \\
\text { centro/Difuso na } \\
\text { periferia }\end{array}$ & $\begin{array}{l}\text { Denso no } \\
\text { centro/Difuso } \\
\text { na periferia }\end{array}$ \\
\hline $\begin{array}{l}\text { Atores mais citados nas } \\
\text { entrevistas }\end{array}$ & Discente/Docente & $\begin{array}{l}\text { Discente/ } \\
\text { Docente }\end{array}$ \\
\hline $\begin{array}{l}\text { Relacionamento mais } \\
\text { intenso }\end{array}$ & $\begin{array}{l}\text { Coord. } \\
\text { Administração/ } \\
\text { Docentes }\end{array}$ & $\begin{array}{l}\text { Coord. } \\
\text { Mecatrônica/ } \\
\text { Docentes }\end{array}$ \\
\hline
\end{tabular}

Fonte: Elaborado pelos autores.
Conforme observado na Figura 2, o recorte avaliado da rede da FAAG é mais denso onde se localizam a Diretoria Acadêmica e as Coordenações de Cursos de Graduação e Pós-Graduação. Nas extremidades, próximo à Diretoria Administrativa e Coordenação de Pós-Graduação em Educação, onde o grau de interconexão é menor, o recorte avaliado da rede é mais difuso, concentrando relacionamentos com atores externos do recorte da rede. $\mathrm{O}$ ator que mais possui ligações associadas a ele e pode ser considerado o ator central do recorte avaliado da rede da FAAG é a Diretoria Acadêmica, citada por todos os outros atores entrevistados.

O recorte avaliado da rede da Fatec Garça apresenta alto grau de interconexão entre a Diretoria Geral, a Diretoria Acadêmica e as Coordenações dos Cursos, sendo mais denso nesta região, conforme se observa na Figura 3. A Diretoria de Serviços e os Coordenadores de Estágio mantêm relacionamentos com os atores externos. No entanto, devido ao baixo grau de interconexão nesta região, pode-se dizer que o recorte avaliado da rede é difuso nas extremidades. $\mathrm{O}$ ator central do recorte avaliado da Fatec Garça é a Diretoria Geral, por apresentar elevado número de ligações com os demais atores entrevistados.

Os relacionamentos com maior intensidade no recorte avaliado da rede da FAAG ocorrem entre as Coordenações de Curso de Graduação e PósGraduação com o corpo discente (ator 52) e o corpo docente (ator 54), entre a Diretoria Acadêmica com 
a Mantenedora e Coordenadores, entre a Diretoria Administrativa com a Mantenedora e entre a Secretaria Acadêmica com o Departamento de Tecnologia de Informação (ator 13).

$\mathrm{Na}$ Fatec Garça, os relacionamentos de maior intensidade ocorrem entre as Coordenações dos Cursos de Graduação com o corpo discente (ator 6) e corpo docente (ator 4), entre a Diretoria Geral com as Coordenações dos Cursos de Graduação, entre a Diretoria Geral, Diretoria Acadêmica e Diretoria de Serviços e entre a Diretoria Acadêmica e a Congregação (ator 3).

Os atores entrevistados do recorte avaliado da rede da FAAG possuem relacionamentos intensos com os setores técnicos da instituição, observados na Figura 2 pelos relacionamentos da Secretaria Acadêmica, da Secretaria de Coordenação (ator 19), Marketing (ator 16), Contabilidade (ator 12) e Recursos Humanos (ator 18) com os atores entrevistados. Mas essa intensidade entre relacionamentos não é observada nos relacionamentos, ou ligações, entre os próprios atores entrevistados.

Ao analisar a Figura 3 é possível observar a existência de relacionamentos intensos entre os atores entrevistados dos níveis estratégico e tático da Fatec Garça. Os Coordenadores de Estágio da Fatec Garça, no uso das suas atribuições, podem contribuir para o alcance dos objetivos estratégicos propostos pela instituição. Tais Coordenadores de Estágio apontaram o relacionamento com cerca de 90 atores externos, enquanto a Diretoria de Serviços, responsável pelas questões financeiras da instituição, mantém relacionamento com aproximadamente 40 atores externos.

\section{Considerações finais}

Com a utilização da abordagem proposta na Tabela 1, foi possível conhecer a dinâmica dos relacionamentos entre os atores do recorte avaliado da rede da FAAG e da rede da Fatec Garça, pois houve conhecimento das principais atividades por eles desenvolvidas nos níveis estratégico e tático, além de levantar a importância de cada uma mediante a aplicação do conceito cliente-fornecedor proposto por Gattorna e Walters (1996). Conhecendo as principais atividades dos atores entrevistados, foi possível verificar quais atores estão se relacionando com maior ou menor intensidade. Conforme observado no Quadro 3, os relacionamentos mais intensos na FAAG ocorrem entre a Coordenação de Administração com o corpo docente e, na Fatec Garça, entre a Coordenação de Mecatrônica com o corpo docente.

Apesar de relacionamentos fracos ou com menor intensidade serem favoráveis para o acesso a informações e recursos que propiciem a inovação, os relacionamentos fortes ou com maior intensidade privilegiam a acessibilidade às informações e relacionamentos mais confiáveis.

Nas duas IES foi possível evidenciar a preocupação com o corpo discente e com o corpo docente, ficando evidente a existência de relacionamentos que denotam a preocupação com os aspectos didático-pedagógicos. No entanto, observa-se que, comparando a intensidade dos relacionamentos entre as Coordenações de Cursos das instituições pesquisadas, as Coordenações da Fatec Garça possuem relacionamentos mais intensos que as da FAAG.

Ao considerar a área da educação, em especial a educação superior com suas variáveis sob a ótica de redes de empresas, novas pesquisas podem ser desenvolvidas visando ao enriquecimento de conhecimentos científicos.

\section{Referências}

BRITTO, J. N. P. Cooperação interindustrial e redes de empresas. In: KUPFER, David; HASENCLEVER, Lia (Org.). Economia industrial: fundamentos teóricos e práticos no Brasil. 2. ed. Rio de Janeiro: Campus, 2002.

INEP - Instituto Nacional de Estudos e Pesquisas Educacionais Anísio Teixeira (Brasil). Disponível em: <http://portal.inep.gov.br/web/censo-daeducacao-superior/resumos-tecnicos $>$. Acesso em: 31 jan. 2012.

FUSCO, J. P. A.; BUOSI, G. R. C.; RUBIATO, R. Modelo de redes simultâneas para avaliação competitiva de redes de empresas. Gestão e Produção, São Carlos, v. 12, n. 12, p. 151-163, 2005. Disponível em: <http://www.scielo.br/pdf/gp/v12n2/26085.pdf $>$.

Acesso em: 6 maio 2010.

GATTORNA, J. L.; WALTERS, D. W. Managing the supply chain: a strategic perspective. London: Mac Millan Press Limited, 1996.

GRANOVETTER, Mark. The strength of weak ties. Sociological Theory, the American Journal of Sociology, v. 78, p. 1360-1380, 1973. Disponível em: <http://www.jstor.org/stable/2776392>. Acesso em: 5 set. 2010. 
The strength of weak ties: a network theory revisited. Sociological Theory, John Wiley \& Sons, v. 1, p. 201-233, 1983. Disponível em: <http://www.jstor.org/stable/202051 ?origin=crossre f>. Acesso em: 14 jun. 2011.

LAZZARINI, Sérgio G. Empresas em rede. São Paulo: Cengage Learning, 2008.

LIMA, Francisco Paulo de Oliveira. Proposta de uma abordagem metodológica para analisar como os fatores posicionais influenciam as prioridades competitivas. 2009. Dissertação (Mestrado em Engenharia de Produção) Universidade Estadual Paulista "Julio De Mesquita Filho", Bauru, SP, 2009.

MIGUEL, P. A. C. Adoção do estudo de caso na engenharia de produção. In: MIGUEL, Paulo; CAUCHICK, A. (Org.). Metodologia de pesquisa em engenharia de produção e gestão de operações. Rio de Janeiro: Elsevier, 2010.

SACOMANO NETO, M. Redes: difusão de conhecimento e controle - Um estudo de caso na indústria brasileira de caminhões. 2004. Tese (Doutorado em Engenharia de Produção) Universidade Federal de São Carlos, São Paulo, 2004.

Artigo selecionado entre os 10 melhores do VIII Encontro Mineiro de Engenharia de Produção

- EMEPRO 2012. 